\title{
Interstitial pregnancy near term with uterine torsion
}

\author{
MS Waghmare \\ Correspondence: Dr MS Waghmare, Assistant Professor, Department of Obstetrics and \\ Gynaecology, Seth GS Medical College and KEM Hospital, Mumbai, Maharashtra, India; \\ Email - drwmamata@gmail.com
}

Distributed under Creative Commons Attribution-Share Alike 4.0 International.

\begin{abstract}
The objective of this case report is to describe a rare case of interstitial pregnancy continued till third trimester undergone uterine torsion. A 34 years primigravida with 31 weeks gestation was referred to our hospital with pain in abdomen and uterine tenderness. The presumptive diagnosis was a concealed placental abruption. Patient was taken for emergency caesarean section in view of failure of induction. During caesarean section diagnosis of uterine torsion and interstitial pregnancy was established. Post operative patient recovered well and discharged on seventh postoperative day. So, if interstitial pregnancy is not diagnosed at an early gestation age, it may continue till term which may lead to a rare complication of uterine torsion.
\end{abstract}

Keywords: Interstitial pregnancy, uterine torsion, placental abruption.

Uterine torsion during pregnancy is rare. Uterine torsion and interstitial pregnancy as single event rarely reported in literature. Prevalence of interstitial pregnancies is $2 \% .{ }^{1}$ Because of increased distensibility of interstitial part, pregnancy may remain asymptomatic and unruptured until 14 to 16 weeks gestation. ${ }^{1}$ As the symptom complex of uterine torsion is nonspecific, and as surgical exploration is normally required to establish the correct diagnosis, intervention is frequently delayed, increasing the risk of complications. Certain maternal irregular body movements or posture and position may cause rotation of uterus with underlying predisposing factors for rotation. Uterine venous obstruction causes increased pressure in placental cotyledons leading to abruption and fetal distress and uterine artery obstruction leads to reduced placental perfusion which can lead to fetal demise.

\section{Case Report}

A 34 year old primigravida 31 weeks of gestation with a singletone pregnant woman was referred from periphery hospital in view of acute abdominal pain with intrauterine fetal demise. Patient was admitted in periphery hospital for evaluation and correction of anemia with $\mathrm{Hb}$ of 6.4 gm\%. Next day morning patient had sudden onset acute pain in abdomen with breathlessness. She arrived to our hospital with uterine cramping pain and absent fetal movement.

On examination, pulse was 64 beats per minutes; blood pressure was 90/70 $\mathrm{mmHg}$, pallor present. The uterus was 36 weeks size which was unusual, tense and was severely tender on palpation. The fetus was in longitudinal lie with cephalic presentation. The fetal heart sound was absent. There was no vaginal bleeding. On vaginal examination cervix was firm in consistency and

Received: 1 st April 2017 . Accepted: 24 th October 2017.

Waghmare MS. Interstitial pregnancy near term with uterine torsion. The New Indian Journal of OBGYN. 2018; 4(2): $168-70$. 
no effacement and dilatation. The presumptive diagnosis was a concealed placental abruption.

Ultrasound showed absent fetal heart rate and no retroplacental hematoma. Coagulation profile was normal. Other blood investigations were within normal limits. Cerviprime induction of labour was done. There was failure of cervical dilatation despite strong uterine contractions, so decision of emergency caesarean section was taken. Patient received three blood transfusions preoperatively. Under spinal anesthesia, an infraumbilical midline vertical incision was made. On entering the abdominal cavity, bladder flap was not visualized. The right round ligament, ovary, and fallopian tubes appeared to be rotated from left to right. Transverse lower segment uterine incision was made and presenting part was high and with difficulty baby was delivered. There was no placental abruption. The placenta was removed manually.

The uterus brought through the abdominal incision, uterine torsion was found. Uterus derotated $180^{\circ}$. The incision on uterus was on posterior surface. At the time of surgery, the uterine fundus on right side was found to be enlarged, myometrium thinned out, with a discolored cystic swelling. We suspected interstitial pregnancy. There was no other uterine anomaly or pelvic pathology. There was no other reason for uterine torsion. The uterine incision was closed with a double layer of delayed absorbing suture (polyglactin 910).

The patient made an uneventful recovery and was discharged home on the seventh postoperative day. The patient was advised to undergo caesarean section for any subsequent deliveries because of the lack of information about the safety of labour following a posterior lower segment uterine incision. We failed to get early post operative MRI of the patient due to affordability issue. MRI was done day 20 post operative.

\section{Discussion}

An interstitial pregnancy is type of ectopic pregnancy in which pregnancy is located outside of the uterine cavity in that part of the fallopian tube that penetrates the muscular layer of the uterus. ${ }^{2}$ Few case reports of term interstitial pregnancies have been reported, and none have been associated with fetal survival. In our case pregnancy continued till third trimester but due to pathological rotation of uterus intrauterine fetal death occurred.
The exact mechanism and etiology of uterine torsion is not known. The predisposing factors found in some of these cases are malpresentation of the fetus (especially transverse lie), myomas, uterine anomalies, pelvic adhesions, ovarian cysts, uterine suspension, abnormal pelvis and placenta previa. ${ }^{3}$ According to Wilson et al. ${ }^{4}$ most of cases had normal anatomy that is unexplained torsion. In most case reports, the correct diagnosis was rarely established before surgical exploration. Torsion is also rarely asymptomatic. ${ }^{5}$ Recently, both magnetic resonance imaging and computed tomography scanning have been used to help make the diagnosis prior to exploratory surgery. Torsion of the full term pregnant uterus is a rare obstetric event and rarely diagnosed before surgery. It can be asymptomatic or may present with acute onset of abdominal pain, distention, gastrointestinal disturbances, urinary dysfunction and vaginal bleeding.

Management requires emergency laparotomy. At term, uterus is derotated and LSCS (lower segment caesarean section) is done. If derotation is not possible, posterior low transverse incision is given. ${ }^{6}$ In such cases elective section is advised in next pregnancy as risk of rupture is not known. ${ }^{4}$ Fetal mortality of $18 \%$ was reported by Wilson et al. ${ }^{4}$

Diagnosis of an interstitial pregnancy can be missed by either physical examination or ultrasound. Recently, both magnetic resonance imaging and computed tomography scanning have been used to help make the diagnosis prior to exploratory surgery. ${ }^{7}$ If interstitial pregnancy is not diagnosed at an early gestation age, it may continue till term which may lead to a rare complication of uterine torsion.

\section{Conflict of interest: None. Disclaimer: Nil.}

\section{References}

1.Cunningham FG, Leveno KJ, Bloom SL, Hauth JC, Rouse DJ, Sponge CY. "Ectopic pregnancy," in Williams Obstetrics. 23rd edition. New York: McGraw-Hill; 2010. p. 238-56.

2.Moawad NS, Mahajan ST, Moniz MH, Taylor SE, Hurd WW. Current diagnosis and treatment of interstitial. American Journal of Obstetrics \& Gynecology. 2010; 202(1): 15-29. [PubMed] 
The New Indian Journal of OBGYN. 2018 (January-June); 4(2)

3.Greening JR, Beck RP. Torsion of the pregnant uterus report of a case. Obstet Gynecol. 1963; 21: 420. [PubMed]

4.Wilson D, Mahalingham A, Ross S. Third trimester uterine torsion: case report. Journal of Obstetrics and Gynecology Canada. 2006; 28(6): 531-35.

5.Dandawate B, Carpenter T. Asymptomatic torsion of pregnant uterus. J Obstet Gynecol. 2006. 26(4):375-6. [Medline]

6.Albay Rak M, Berian A, Ozdenir I, Deniraran Y, Guralp O. Deliberate posterior low transverse incision at cesarean section of gravid uterus in $180^{\circ}$ of torsion: a case report. Journal of Reproductive Medicine. 2011; 56(3):181-83.
7.Nicholson WK, Coulson CC, McCoy MC, Semelka RC. Pelvic magnentic resonance imaging in the evaluation of uterine torsion. Obstet Gynecol. 1995. 85(5 Pt2): 888-90. [Pubmed]

\section{MS Waghmare ${ }^{1}$}

${ }^{1}$ Assistant Professor, Department of Obstetrics and Gynaecology, Seth GS Medical College and KEM Hospital, Mumbai, Maharashtra, India 